\title{
Idea Management in a Digital World: An Adapted Framework
}

\author{
Désirée Krejci \\ HEC University of Lausanne \\ desiree.krejci@unil.ch
}

\author{
Stéphanie Missonier \\ HEC University of Lausanne \\ stephanie.missonier@unil.ch
}

\begin{abstract}
The continuing emergence of new digital technologies, platforms and infrastructure has opened unprecedented possibilities for innovation. Eager to seize these opportunities, many organizations adopt idea management programs to help leverage their employees' ideas for digital innovations. However, we lack an integrated understanding of how the logics of digital innovation affect the practice of idea management. We therefore pose the following research question: "How can idea management programs be conceptualized in light of digital innovation?". Drawing on the disparate yet complementary conceptual building blocks of open innovation and problem-solution pairs, we develop a revised conceptualization of how idea management is practiced in a digital context. Our framework suggests that idea management programs can be used by organizations as orchestration and cognitive sensemaking devices to support the matching, forking, merging and refinement of ideas. These insights shed fresh light on how innovations form and evolve in a pervasively digital world.
\end{abstract}

\section{Introduction}

Despite an increasing pressure to apply digital technologies to transform their offerings, many organizations struggle to leverage their employees' full potential in digital innovation efforts [1]. Against this backdrop, organizations are increasingly turning to idea management programs to help successfully source, select and develop their employees' ideas [2]. As a result, the focus of idea management programs has broadened from collecting ideas for local improvements to instigating digital innovation with ordinary employees, causing digital technologies to become increasingly entangled with the practice of idea management [2].

Scholars have repeatedly highlighted that the pervasive use of digital technology in innovation processes and outcomes changes the nature of innovation in such ways that it needs to be studied as a phenomenon that is fundamentally different from traditional innovation [3, 4]. It has for instance been noted that digital innovation is more generative and convergent in nature, calling into question some of the core assumptions that underlie the traditional innovation management literature [3]. Idea management is a critical sub-process of innovation management that is critically affected by these evolutions [5]. Indeed, the literature is sprinkled with instances of idea management processes and actors being impacted by the pervasive use of digital technology. Yet, state-of-the-art conceptualizations still assume a traditional approach to idea management (i.e. delimited phases and predefined actors [2]) which yields a poor fit with the changing nature of innovation [6], thus warranting a revision. In view of the pressing need for organizations to successfully turn their employees' ideas into digital innovations, we explore the research question: "How can idea management programs be conceptualized in light of digital innovation?".

We address our research question in two steps. First, we leverage the conceptual building blocks of open innovation and problem-solution pairs to deductively develop an initial framework of idea management in light of digital innovation. Second, we validate our initial framework against a revelatory case of how idea management programs are used to create digital innovations with employees, and we inductively refine our initial framework by accounting for discrepancies between the framework and the case data. This deductive-inductive approach allows for "contradictory observations to change what we know" [7, p. 3] and is therefore a good methodological fit to extend our understanding of idea management in light of digital innovation.

Our main contribution to research and practice is a conceptual framework that integrates disparate yet complementary conceptual lenses (open innovation

[8] and problem-solution pairs [9]) and provides a revised understanding of how idea management is how innovations form and evolve in a pervasively digital world [3] by suggesting that idea management programs can act as sensemaking and orchestrating devices when creating digital innovations. This fresh 
perspective on idea management presents an exciting starting point to guide management practices in the age of digital innovation with revised theoretical models.

This paper is structured as follows: in Section 2, we provide an overview of the idea management literature and propose two conceptual lenses (i.e. open innovation and problem-solution pairs) that help extend our understanding of idea management with regard to digital innovation. Drawing on these conceptual lenses, we present in Section 3 our initial framework of idea management in light of digital innovation. In Section 4, we describe our study design and introduce the case upon which we test and refine our initial framework. In Section 5, we present our findings and propose a refined version of our initial framework. We discuss our findings in Section 6 and conclude in Section 7.

\section{Background}

Idea management is not historically new and has attracted both practitioners' and researchers' interest for some decades now [10]. Since its inception in the manufacturing industry in the 18th century [11], idea management has crystalized as "one of the most persistent management concepts ever" [12, p. 238] by continuously adapting to changes in its economic, social, and technological environment. Idea management programs are a combination of process phases, actors and technological tools that organizations adopt to stimulate the generation of ideas and support their development into valuable outcomes [5]. Owing to shifts in the competitive landscape, the scope of idea management programs has gradually broadened from surfacing ideas for local improvements (e.g. via idea boxes) to empowering corporate employees in their innovation efforts (e.g. via innovation contests). A growing number of organizations leverage idea management programs to empower their employees to create digital innovations specifically [1]. As a result, the use of digital technologies is pervading idea management both in its process and its outcomes.

Scholars have repeatedly highlighted that the use of digital technologies in innovation processes and subprocesses challenges our understanding of how innovations form and evolve [3]. The conceptualization of idea management as one such sub-process is most certainly affected by these considerations [5] but we as yet have a fragmented understanding of how the new logics of digital innovation alter the management of ideas.

We identify two key trends in how the changing nature of innovation affects the practice of idea management within organizations. First, the malleable nature of digital artefacts and the use of digital prototyping techniques (e.g. 3D printing) make it possible to develop ideas in a more emergent manner with overlapping idea improvement, evaluation and selection phases [13]. Second, the use of digital platforms (e.g. crowdsourcing platforms) allows to involve a more emergent constellation of intra- and extra-organizational actors, (e.g. employees or customers) in the generation, development, and selection of innovative ideas [6, 14]. These two evolutions have been reported somehow disjointedly in the information systems and innovation management literature, yet overall they confirm a general trend towards a more fluid idea development process (i.e. temporal overlaps between phases) involving more dynamic actors (i.e. emergent participation), both triggered by the transition from innovation to digital innovation $[3,4]$.

Notwithstanding these evolutions, current conceptualizations of idea management still assume a stage-gate process with delimited phases and predefined actors, and thus largely overlook how idea management is impacted by the changing nature of innovation. This is reflected in a recent consolidation of the literature by Gerlach and Brem [2] that depicts idea management as a process with six clearly defined consecutive phases (i.e. preparation, idea generation, improvement, evaluation, implementation, and deployment) each involving a predefined set of actors (i.e. idea manager, ideator, discussion group, and idea selector). While this conceptualization offers valuable insights into the practice of idea management, it yields a poor fit with the emergent nature of digital innovation processes and actors and provides little guidance in the current context of pervasive digitalization. We thus scan the IS and management literature for additional concepts that reflect the new logics of digital innovation, with a particular focus on concepts that have been used to capture the shift towards fluid processes and dynamic actors when creating digital innovations. We identify open innovation and problem-solution pairs as useful conceptual lenses and justify this choice in the following two sub-sections.

\subsection{Open innovation}

Open innovation describes "a distributed innovation process based on purposively managed knowledge flows across organizational boundaries" [15, p. 17]. The term "open innovation" was first coined to illustrate how the boundaries within which innovation traditionally takes place in organizations are eroding and lead to more distributed models of innovation [8]. The phenomenon has gained considerable attention among scholars and many have highlighted how open knowledge exchange between a firm and its environment, as well as within a firm, can accelerate 
innovation [16]. Open innovation has notably been linked to users as innovators [17], innovation communities [18] and open source software development [19]. Common to these various innovation-related phenomena is the finding that ideas are a key vehicle for knowledge exchange between various innovation contributors, suggesting that open innovation is a useful conceptual building block to examine the management of ideas. Additionally, open innovation has been highlighted as a powerful lens to investigate employees' role in a more distributed innovation process [3], suggesting its value for the study of idea management in a digital context.

The most common conceptualization of open innovation is a permeable funnel where innovative ideas enter on the wide side and innovative outcomes exit on the narrow side [8]. Knowledge can be sourced into or extracted from the funnel at any point, thus accounting for the "openness" of the innovation process (visually depicted by multiple perforations in the funnel's wall). These knowledge exchanges imply that a greater diversity of an organization's internal and external actors can dynamically join in and retract from the innovation process. Furthermore, the open funnel departs from traditional stage-gate models by acknowledging that dynamic knowledge exchanges cause innovations to evolve in a non-linear manner. To depict these new levels of fluidity, formal stage-gates are substituted for loosely defined phases along the funnel [16].

The open innovation lens has recently been leveraged to highlight the emergent nature of actors developing digital innovations. Some examples are [14] and [20] who draw on open innovation in their exploration of crowdsourcing initiatives and open source digital innovation. While the open innovation lens has proven valuable in exploring the digital innovation process as a whole, it has not yet been leveraged to revise our conceptualization of the critical early phases of digital innovation initiation and the practice of idea management.

\subsection{Problem-solution pairs}

Problem-solution pairs have their roots in design research where they originally highlight the coevolution of problem and solution spaces in creative design $[21,22]$. The concept has been picked up and further developed in the decision-making literature as "need-solution pairs" [9] and as "problem-solution pairs" in the digital innovation management literature [3]. Problem-solution pairs primarily account for the fact that innovation actors view the initial problem statement as a variable rather than a fixed objective. Consequently, innovations are a constant search not only for the most relevant solution to a given problem but also for the most relevant problem to be solved. This search process can be conducted by individuals within or outside an organization's boundaries [9].

Problem-solution pairs are most commonly conceptualized as dynamic couplings of a problem and a solution that evolve by establishing new and discarding obsolete links with other problems and solutions [23]. Problems refer to latent needs, while solutions refer to artifacts, their features and functionalities. An innovative idea can be conceptualized as a set, or network, of interlinked problems and solutions. Moreover, it suggests that trialand-error cycles (e.g. via rapid prototyping methods) are a powerful way to identify the most relevant problemsolution pairs and thus the most promising ideas [9].

The conceptual lens of problem-solution pairs has recently been applied to digital innovation research [23] to capture the dynamic relationship and mutual influence between user needs (i.e. problems) and digitalized artifacts (i.e. solutions) when creating digital innovations. It has notably been noted that digital innovation management and its sub-processes should be studied as "a sporadic, parallel, and heterogeneous generation, forking, merging, termination, and refinement of problem-solution design pairs" [3, p. 226], where the concept of problem-solutions pairs helps capturing the dynamic evolution of ideas' underlying components. Digital innovation processes being more emergent in nature, we suggest that problem-solution pairs are a promising conceptual building block for the study of idea management in a digital context.

Considering the above-mentioned merits and shortcomings of the extant literature, we view open innovation and problem-solution pairs as valuable conceptual building blocks that can help reflect the emergent nature of idea management process phases and actors in a digital innovation context (Figure 1).

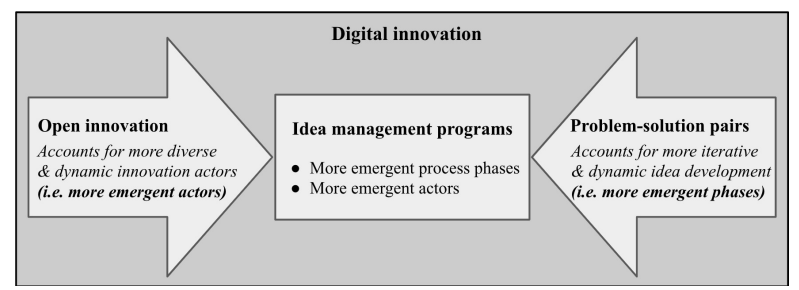

Figure 1. Research approach

\section{Initial framework}

We rely on the existing literature to develop our initial framework of how idea management is practiced in a digital context. Specifically, we leverage the disparate but complementary conceptual building blocks of idea management, open innovation and 
problem-solution pairs to account for the trend towards more emergent idea management processes and actors in light of digital innovation.

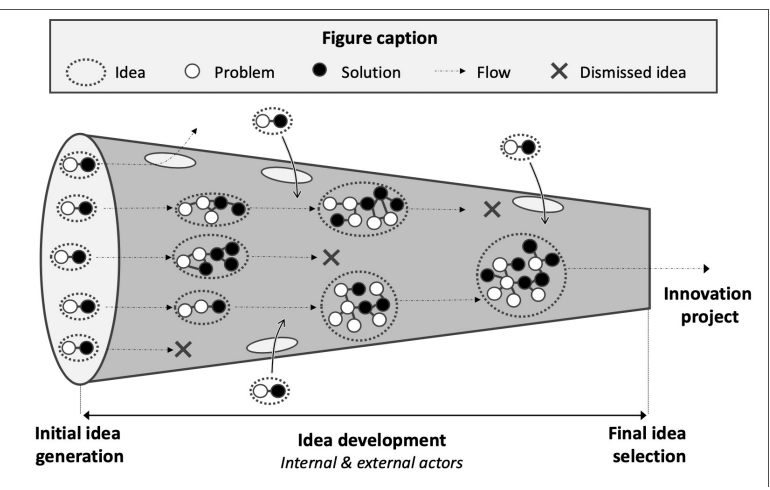

Figure 2. Initial framework

In Figure 2, we draw on the three above- mentioned building blocks in the following ways:

- Idea management: An idea management program is represented as a funnel where ideas are generated (i.e. wide end; large number of ideas), developed (i.e. inside the funnel; decreasing number of ideas) and selected for implementation as innovation projects (i.e. narrow end; small number of ideas) by actors taking the roles of ideators, idea managers and idea selectors.

- Problem-solution pairs: Ideas (i.e. dotted circles) are represented as matching pairs of problems (i.e. white circles) and solutions (i.e. black circles) that dynamically evolve into networks as new problems and solutions are sporadically discovered or discarded over time.

- Open innovation: Perforations in the wall of the funnel depict that ideas can be sourced from, and outsourced to, actors external to the program (e.g. startups, customers, corporate employees not directly involved in the program) at any time during idea development.

Next, we study an empirical case to guide the refinement of our initial framework. In our case study, we put a strong analytical focus on two aspects of our initial framework: (1) the emergent nature of actor participation (i.e. the punctual involvement of an emerging collection of idea contributors in the idea management process) and (2) the dynamic nature of the idea management process (i.e. the management of ideas as the management of problem- solution pairs that continuously and dynamically evolve into problemsolution networks).

\section{Research Methodology}

Idea management is a complex phenomenon that requires the investigation of a rich data set [24]. We performed an in-depth longitudinal case study of a traditional organization (i.e. Globex; name changed) that had deployed an idea management program to enable and support its employees when creating digital innovations. Considering the large body of literature on how ideas are generated and developed in organizations, we took a deductive-inductive approach $[7,25,26]$ that consisted of two steps:

In a first deductive step, we derived an initial framework of idea management from the existing literature by combining the conceptual building blocks of open innovation and problem-solution pairs (i.e. deductive analysis step). In a second inductive step, we looked for contradictions between our initial framework and the Globex case data, and updated our initial framework with missing factors, links, or effect (i.e. inductive analysis step). Our coding scheme thus included both deductive codes aimed at validating the initial framework and inductive codes aimed at refining the initial framework.

The outcome of these two steps is a revised conceptual framework of idea management in the context of digital innovation. This framework integrates existing knowledge about idea management that has been confirmed by our case, while also accounting for new insights that could not be explained by the existing literature.

\subsection{Case selection}

We selected the case of an incumbent firm in the fragrance industry with approximately 7'000 employees, i.e. Globex (name changed). At the time of the study, Globex had deployed an idea management program to enable and support its employees when they create digital innovations. Importantly, we view our case as a "common" case rather than an "ideal" case of how idea management is performed to spur the creation of digital innovations with employees. Our case selection is thus in line with our research aim, i.e. that of performing an explorative study on an emerging realworld phenomenon (i.e. idea management for digital innovations) and to capture our insights in an initial descriptive framework.

We gained access to the case through an associate researcher who was employed for a period of six months to support Globex's innovation activities with an assigned a role in the idea management program. Given that an intra-organizational level of analysis (e.g. programs, business units, functional departments) was considered particularly salient in understanding the 
sources of innovation [27], we chose to focus on Globex's idea management program (in terms of process, actors and technology) as our primary research object.

Globex operates as a leading multinational company in the perfumery market. In recent years, the firm sensed that rapidly changing customer preferences and unprecedented technical possibilities were shaking up the industry of perfume creation and distribution. In particular, heavily digitizing competitors were putting the firm under growing market pressure. In an effort to maintain its dominant position, Globex's executive board decided to sharpen its strategic focus on digital innovation. In 2017, the company set up a digital innovation department directly overseen by the executive board with the primary mission to accelerate the development of ideas into digital innovations. The department was based in the information systems department but acted as a transversal support unit for all organizational departments. As of March 2020, the digital innovation department comprised seven full-time employees.

Upon its creation, the digital innovation department launched an idea management program to encourage corporate employees to create digital innovations (i.e. innovative products, services and processes with digital core components). Previously, Globex was lacking a systematic way to manage employees' ideas, leaving idea management entirely to individual line managers. The department adopted an idea management system to collect, store and track ideas. All employees were given access to the idea management system to view idea campaigns, submit ideas, view status updates and provide feedback on ideas. Overall, ideas were sourced from two channels: internal idea campaigns and workshops.

Over the time of our study, the department facilitated three idea campaigns and two dozen innovation workshops, and was managing several hundred ideas for digital innovation throughout the course of this study.

\subsection{Data collection}

Table 1 provides an overview of our data sources. We started interacting with our case in March 2019. Within one year, we conducted 22 semi-structured interviews with 6 key members of the digital innovation department and 5 stakeholders in idea campaigns (interview details available upon request). All interviews followed a flexible guideline around the practice of idea management and the use of digital technologies in its process and outcome. Additionally, we gathered a significant amount of secondary data from the digital innovation department in the form of internal documents (e.g. formalizations of the idea management process, lessons-learned, idea campaign project pitches) and field notes. To gain a richer understanding of this data, we attended one full day innovation workshop facilitated by the digital innovation department and took notes during several informal discussions with members of the innovation department before/after formal interviews and observations. We were also granted access to the idea management system that was used to track idea campaigns. This gave us an in- depth view of the types of ideas that had been submitted, who had submitted them and how they were being developed. Moreover, we drew on written reports from, and regular oral debriefings with, the above-mentioned associate researcher who performed six months of participantobservation (February to July 2019) in Globex's digital innovation department.

Table 1. Data sources

\begin{tabular}{|c|c|c|c|}
\hline Source & Type & Total & \# pages \\
\hline \multirow{2}{*}{ Interviews } & On site face-to-face & 15 & \multirow{2}{*}{$\begin{array}{r}135 \\
(23 \mathrm{~h}) \\
\end{array}$} \\
\hline & Remote video calls & 7 & \\
\hline \multirow{3}{*}{$\begin{array}{l}\text { Internal } \\
\text { documents }\end{array}$} & C-level briefings & 3 & \multirow{3}{*}{110} \\
\hline & Lessons learned & 2 & \\
\hline & Idea pitches & 2 & \\
\hline Observation & Full day workshop & 1 & $5(8 h)$ \\
\hline Field notes & Unstructured notes & 4 & 15 \\
\hline \multirow{2}{*}{$\begin{array}{l}\text { Idea mgmt } \\
\text { system }\end{array}$} & Idea database & 1 & - \\
\hline & Participant database & 1 & - \\
\hline \multirow{2}{*}{$\begin{array}{l}\text { Participant- } \\
\text { observation }\end{array}$} & Written report & 1 & 10 \\
\hline & Oral debriefings & 10 & 3 \\
\hline
\end{tabular}

\subsection{Data analysis}

Following our deductive-inductive research approach [7], we operationalized our initial constructs and derived a coding list of six thematic codes specific to idea management [2] (i.e. idea, phase, actor, funnel, outcome, organizational environment), three thematic codes specific to digital innovation management $[3,4]$ (i.e. digital technology, temporal fluidity, dynamic participation) and six thematic codes specific to our conceptual building blocks $[8,9]$ (i.e. problem, solution, problem-solution pair, problem-solution network, ingoing ideas, outgoing ideas). Each thematic code was further derived into multiple sub-codes to guide our analytic focus. Drawing on deductive analysis, we first coded our data top-down according to this coding list [28] and verified for fits and misfits between our initial framework and the data. As a second step, we reexamined the data with a bottom- up inductive coding approach to uncover potential discrepancies between 
our initial framework and the data. This yielded six additional inductive codes (i.e. idea matching, idea forking, idea merging, idea refinement, single problem/solution, kite-shaped funnel). Finally, we refined our initial framework with the newly emerged factors, links and effects.

\section{Findings and refined framework}

In order to make the link between our framework and the case analysis more evident for the reader, we first present our refined framework and highlight how it differs from our initial framework before we turn to the empirical insights that guided its refinement.

\subsection{Refined framework}

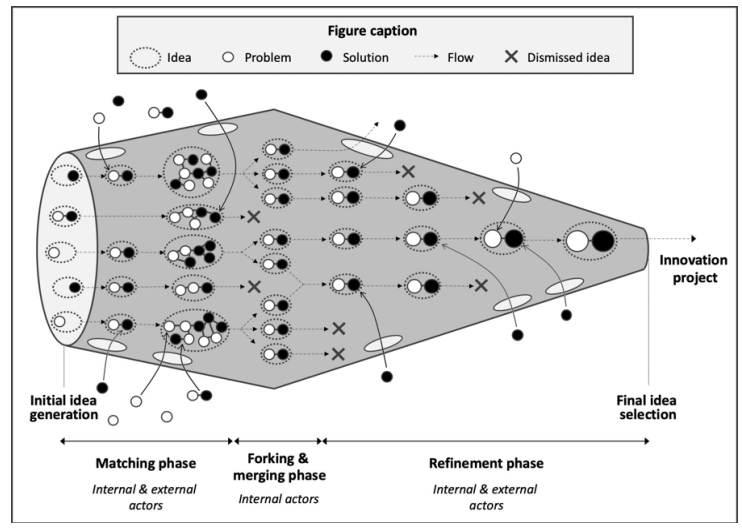

Figure 3. Refined framework

Our refined framework (Figure 3) differs from our initial framework (Figure 2) by acknowledging for: (1) the sourcing of ideas as single problems, single solutions or problem-solution pairs (initial idea generation), (2) the sporadic matching, un- matching and re-matching of problems and solutions into pairs and networks in the early stages of the idea management funnel (matching phase; internal \& external actors), (3) the forking and merging of ideas when problem-solution networks become too complex to manage (forking and merging phase; internal actors), (4) the linear refinement of fixed problem-solution pairs in the late stages of the funnel (refinement phase; internal \& external actors), and (5) the increasing and decreasing number of ideas in the funnel (kite-shaped funnel).

We structured the following sub-sections into key confirming, contradicting and extending case data that guided the development of our initial framework into our refined framework. We exemplify the key data with direct quotes from our interviewees for a richer narrative of our focal phenomena.

\subsection{Key confirming data}

We found confirming evidence for the emergent nature of actor participation in idea management programs. Specifically, we observed that the digital innovation department encouraged ideators to collect feedback from colleagues and to have conversations with existing or potential customers, suppliers and partners, to examine the ins and outs of their idea. When asked about the development process of her idea, an employee and idea campaign participant recalled: "We got out of the office, we went to visit patients, to see doctors and therapists' offices. You learn that there are so many opportunities. We did prototypes to get some ideas in front of these people and get their feedback." (Creative perfumery director, July 11. 2019)

This loosely connected collection of internal and external actors punctually took on the roles of idea generators, idea contributors and/or idea selectors. Rather than being formally defined in advance, the attribution of roles occurred implicitly and often unpredictably depending on the type of knowledge that each individual could provide. Our findings thus reflect the trend towards an open idea management crowd and confirm the presence of perforations in the idea management funnel.

Moreover, we found confirming evidence for the dynamic nature of the idea management process. Specifically, we observed that ideas were not managed as static self-contained concepts but rather as dynamically evolving couplings of problems and solutions. The idea management program served as a venue to dig deeper into an idea's underlying problem (i.e. latent need) and solution (i.e. digital artifact). We found a strong reliance on prototyping and design thinking techniques to unearth and make sense of ideas' underlying components. A member of the digital innovation department gave an example of how they made an idea evolve by gradually identifying its problem and solution components: "Since the beginning we were talking to the main stakeholders to understand the idea's scope. We needed to find out the customers' needs and our IS unit's needs. We juggled these two different needs and wondered how we can bring in the technology without making the solution too complex. It's still ongoing, we still need to figure it out. We just went to test our first assumptions." (Innovation lead America, July 9. 2019)

This continuous enrichment of ideas caused overlaps between traditionally well-bounded and sequential idea management process phases. For instance, a member of the digital innovation department highlighted the temporal overlap between the idea improvement, idea evaluation and idea implementation phase: "For idea management, digital technologies 
somehow enable you to keep on refining the need and the solution, while at the same time convincing people in the firm to invest resources." (Innovation specialist, Nov. 22. 2019)

Overall, our findings thus confirm that ideas for digital innovations can be conceptualized as temporary couplings of problems and solutions that evolve via the punctual involvement of an emerging collection of idea contributors in a loosely bounded process.

\subsection{Key contradicting data}

While our case data confirmed the evolution of ideas' underlying problem-solution components, it contradicted the continuously dynamic nature of this evolution. In our initial framework, we had depicted the development of an idea as the ongoing evolution of a problem-solution pair into a problem-solution network, via the sporadic matching of newly discovered problems and solutions. This implied that ideas are continually reassessed and that alternative problems and solutions are considered, if not actively looked for, all along the idea development process. However, our case data suggests that ideas do not evolve dynamically throughout the entire idea development process. While we found strong evidence for dynamic problem-solution matching in the early stages of an idea's development, ideas followed a surprisingly linear refinement process as fixed problem-solution pairs in later development stages. A member of the digital innovation department suggested that this duality derived from the way the firm traditionally managed business projects: "Once you present a promising solution, you've got to deliver something. It's not an option to keep on looking for alternative solutions. You have to show results. On the one hand you have the iterative innovation process, but you also have the decision- making process where everything is oriented towards quickly getting out of this initial phase of uncertainty." (Innovation specialist, Nov. 22. 2019)

While the idea management program encouraged idea experimentation in the early phases of idea development when time and money investments were low, it pushed for results in the later phases when investments were typically higher. The same interviewee alluded to this shift from a logic of dynamic problem-solution matching to a logic of linear problemsolution refinement in saying: "At some point, I need to specify my idea: What technology am I going to use? What process changes does it imply? Imagine I've got three options. I test each one of them. I find new connections with other problems and solutions and this gives me new ideas. At some point, this process needs to stop because we simply don't have the money to develop all possible ideas." (Innovation specialist, Nov. 22. 2020)

At Globex, the moment when ideators needed to move on from a dynamic matching logic to a linear refinement logic was tightly linked with the creation of minimal viable products (MVPs). Importantly, these prototypes included functional digital components and required the intervention of professional programmers. In a context where IT resources are scarce and expensive, the integration of functional digital components motivated the shift from an exploration to an exploitation logic. In the words of the digital innovation department's director: "We used to rush into doing MVPs. Now, we spend quite some time in the preceding stages. We spent about 3 months doing workshops, trying to understand and merge ideas. Right now, we're doing mockups for these 14 ideas to show them to users. There's no working functionality behind. [...] Once we're clear with that, we'll start doing MVPs. Because that's when we start investing money, mostly in developers. And these guys get paid 200'000 a year. Before that, we only invest time." (Digital innovation director, Jan. 17. 2020)

After the development of an MVP, we found that ideas were managed as fixed problem-solution pairs that were gradually enriched with insights stemming from tests with target users and discussions with business managers. Newly discovered problems or solutions that were relevant but radically different were no longer considered. In this phase, each problem-solution pair linearly grew into a refined version of the same problem-solution pair.

Overall, these findings contradict the ongoing evolution of problem-solution pairs into networks and suggest a more static approach to ideas once a certain threshold of development has been reached. Based on these insights, we enrich our initial framework by noting that ideas evolve into networks of problems and solutions in early stages of dynamic problem-solution matching (matching phase) and grow into tangible outcomes in subsequent stages of linear idea refinement (refinement phase).

\subsection{Key extending data}

Beyond confirming and contradicting data, we discovered data that extended our initial framework with fresh insights into the underlying constituents of an idea and the appropriate shape of the idea management funnel. First, we observed that ideas that were sourced into the program weren't necessarily composed of a problem-solution pair but often consisted of a single solution or, conversely, a single problem. The digital innovation department's director explained how these orphan problems and solutions were managed in the 
program: "Often people come up with a solution and they don't necessarily know what problem it solves. That's why we need to take a step back and find out the problem each solution tries to address. We recently succeeded in that by systematically asking: "What is your challenge?"." (Digital innovation director, Jan. 17. 2020)

We thus enrich our initial framework by noting that ideas sourced into the funnel can be composed either of a single problem, a single solution, or a problemsolution pair. Single problems and solutions are matched with other problems and solutions into problem-solution pairs, and further developed into problem-solution networks as ideas are discussed and tested with internal and external stakeholders.

Second, our case showed that problem-solution networks contain large amounts of valuable information and harbor many innovation opportunities. The abundance of information that is encapsulated in idea networks added substantial complexity to their management. Actors internal to the idea management program (i.e. ideators and members of the digital innovation department) dealt with this complexity in two ways: they decomposed large problem-solution networks into multiple problem-solution pairs (forking) and united similar problem-solution pairs into one (merging). A member of the digital innovation department explained the forking of ideas in the following way: "An innovation process really is a learning process.

You've got an idea and you draw links with other problems that you hadn't seen before, and that's giving you new ideas. You create all these connections. But then you can't manage this complexity so you break down the idea into smaller parts. You start with one idea and end up with several." (Innovation specialist, Nov. 22. 2019)

The forking of problem-solution networks meant breaking idea networks down into problem-solution pairs that could more easily be apprehended and more readily discussed with internal and external stakeholders. At this point, some promising pairs were sourced out of the program and taken over by business units for further development. Other pairs had strong similarities in their underlying problem and/or solution components, triggering their merging into a single idea. The director of the digital innovation department explained: "We happened to have two ideas dealing with the same problem. We often merged them. Because we realized that a lot of ideas are actually tackling the same pain point." (Digital innovation director, Jan. 17. 2020)

We thus enrich our initial framework by noting that the early phase of dynamic problem-solution matching and late phase of linear problem-solution refinement are linked by an intermediary phase of forking and merging where problem-solution networks are decomposed and/or merged into promising problem-solution pairs. During this intermediary phase the number of ideas increases but decreases again in the subsequent phase, therefore suggesting a kite-shaped funnel. We discuss the overall implications of our refined framework in the next section.

\section{Discussion and outlook}

Our primary aim with this paper was to expand our understanding of idea management in a digital context. We worked towards this goal on several levels. First, we acknowledged the merits and pointed out some shortcomings of the extant literature on idea management with regard to the creation of digital innovations. Second, we proposed two conceptual lenses to help capture the emergent nature of digital innovation processes and actors and leveraged them to build our initial framework of idea management in light of digital innovation. Third, we presented a case of an organization that uses idea management programs to create digital innovations with employees. Guided by the empirical insights we gained from this case, we refined our initial framework. We view the resulting refined framework as our key contribution and as a valuable steppingstone for further research into how digital innovations form and evolve.

Our findings have two main implications for future research. First, our revised framework reveals that idea management is a constant exploration of ideas' underlying problem and solution components that is guided by sporadic feedback from a loosely connected crowd of idea contributors. In helping ideators understand the underlying constituents of their idea, these contributors punctually, and more often than not unconsciously, take on the roles of co- ideators and idea selectors. This collective sensemaking approach is particularly salient in a context where digital solutions can span multiple traditional product categories and where individuals often struggle to understand their underlying purpose [29, 30]. In this context, the meaning of a novel idea is not determined solely by the ideator but rather emerges from the interaction of various social agents who try to understand, share and modify their understanding according to their existing knowledge of similar problems and solutions. Considering the emergent and collective nature of value creation in digital innovation efforts, ideas should be managed in a way that provides venues for punctual comments and feedback among the crowd of idea contributors. In our revised framework, and especially in its matching phase, the idea management program presents such a venue for "open" idea development. 
Firms can use idea management programs as a device for socio-cognitive sensemaking [3] that encourages employees to interact with internal (especially during forking and merging phase) and external stakeholders (especially during matching phase) to more deeply engage with their idea and thoroughly assess its underlying problem and solution components.

Second, our revised framework views ideas as evolving couplings of problems and/or solutions that wait to be revealed by an idea contributor and temporarily matched [9]. The dynamic evolution of ideas causes temporal overlaps in traditional innovation process phases that practitioners must learn to deal with. It has for instance been suggested that digital technologies and/or people can be mobilized to serve as brokers between the numerous problem and solution [31]. In our revised framework, the idea management program takes on this intermediary role, most remarkably in its matching phase and its forking and merging phase. We thus propose that firms can use idea management programs as an orchestration device [3] to match the right problem with an available solution, or the right solution with a known problem. We suggest that idea management programs can help firms to better manage temporal overlaps between traditional innovation process phases, since the orchestrating of problem-solution pairs allows for parallel episodes of idea generation, development, and selection.

Based on these two main implications, we see fruitful research opportunities in examining in more depth how idea management programs can serve as venues for socio-cognitive sensemaking and orchestration devices and how they foster the development of ideas into digital innovations.

We recognize several limitations in our research design. First, we studied a single organization as a revelatory case of how incumbent organizations manage ideas in the context of digital innovation. However, idea management programs might be implemented differently in other organizations, possibly leading to a different conceptualisation [32]. We thus invite our fellow scholars to examine the generalisability of our conceptual framework to other empirical cases. Second, there are complementary approaches to study our focal phenomenon. For instance, studying a single idea as the primary research object for an in-depth investigation of how problem-solution pairs form and evolve in idea management programs, or studying the end-to-end digital innovation process for a more holistic understanding of ideas' evolution. For the purpose of this paper, we deliberately focused on idea management programs as an increasingly prevalent tool and an exciting lever for creating digital innovations with employees. However, we strongly encourage researchers in innovation management and information systems to investigate these alternative approaches to build upon, refute or amend our framework and better capture the critical phenomenon of digital innovation.

\section{Conclusion}

In today's hypercompetitive world, organizations are pressured to harness the innovation potential slumbering in their employees' minds. The lack of clear guidance on the matter led us to reassess the conceptualization of idea management programs. We asked the following research question: "How can idea management programs be conceptualized in light of digital innovation?". Drawing on idea management, open innovation and problem-solution pairs as conceptual building blocks, we perform an in-depth case study of how ideas for digital innovation are managed. Our findings suggest that idea management programs can be used as orchestration and cognitive sensemaking devices to help organizations match, fork and merge, and refine ideas to better meet the digital imperative. Our main contributions are a revised understanding of idea management and a fresh perspective on how innovations form and evolve in a pervasively digital world.

\section{References}

[1] L.E. Opland, L. Jaccheri, I. Pappas, J. and Engesmo, "Utilising the innovation potential - A systematic literature review on employee-driven digital innovation", ECIS proceedings, 89, 2020.

[2] S. Gerlach and A. Brem, "Idea management revisited: A review of the literature and guide for implementation", Int. J. Innovation Studies, 1 (2), 2017, pp. 144-161.

[3] S. Nambisan, K. Lyytinen, A. Majchrzak, and M. Song, "Digital Innovation Management: Reinventing Innovation Management Research in a Digital World", MISQ, 41 (1), 2017, pp. 223-238.

[4] Y. Yoo, "The Tables Have Turned: How Can the Information Systems Field Contribute to Technology and Innovation Management Research?", JAIS, 14 (5), 2013, pp. 227-236.

[5] A. Brem and K.-I. Voigt., "Innovation Management in Emerging Technology Ventures - the Concept of an Integrated Idea Management", Int. J. Technology, Policy and Management, 7 (3), 2007, pp. 6-35.

[6] G. Parker, M.W. Van Alstyne, and X. Jiang, "Platform Ecosystems: How Developers Invert the Firm", MISQ, 2017, pp. 225-266.

[7] J. Gilgun, "Gounded Theory and Other Inductive Research Methods", The Handbook of Social Work Research Methods, 2001, pp. 345-364.

[8] Chesbrough H.W., Open Innovation: The New Imperative for Creating and Profiting from Technology, Harvard Business School Press, Boston, 
2003.

[9] E. von Hippel and G. von Krogh, "Identifying Viable 'Need-Solution Pairs': Problem Solving Without Problem Formulation", Organization Science, 27 (1), 2015, pp. 207-221.

[10] N. Thom, "Idea Management in Switzerland and Germany: Past, Present and Future", Die Unternehmung, 69 (3), 2015, pp. 238-254.

[11] N. Thom and M. Etienne, "Bertiebliches Vorschlagswesen: vom klassischen Modell zum modernen Ideen-Management", 1997, pp. 564-570.

[12] N. Thom, "Innovation Management in Small and Medium-Sized Firms", Management International Review, 1990, pp. 181-192.

[13] T. Rayna and L. Striukova, "From rapid prototyping to home fabrication: How 3D printing is changing business model innovation", Technological Forecasting and Social Change, 102, 2016, pp. 214 224.

[14] D. Schlagwein and N. Bjorn-Andersen, "Organizational Learning with Crowdsourcing: The Revelatory Case of LEGO", JAIS, 15 (11), 2014, pp. 754-778.

[15] Chesbrough H., and M. Bogers, Explicating Open Innovation: Clarifying an Emerging Paradigm for Understanding Innovation, Oxford Press, 2014.

[16] Chesbrough H., Open Innovation: A New Paradigm for Understanding Industrial Innovation, Oxford Press, 2006.

[17] M. Bogers, A.-K. Zobel, A. Afuah, et al., "The open innovation research landscape: established perspectives and emerging themes across different levels of analysis", Industry and Innovation, 24 (1), 2017, pp. 8-40.

[18] L. Fleming and D.M. Waguespack, "Brokerage, Boundary Spanning, and Leadership in Open Innovation Communities", Organization Science, 18 (2), 2007, pp. 165-180.

[19] G. von Krogh, S. Haefliger, S. Spaeth, and M.W. Wallin, "Carrots and Rainbows: Motivation and Social Practice in Open Source Software Development", MISQ, 36 (2), 2012, pp. 649-676.

[20] A. Aagaard, "A theoretical model of supporting open source front end innovation through idea management", Int. J. Business Innovation and Research, 7 (4), 2013, pp. 446-465.

[21] K. Dorst and N. Cross, "Creativity in the design process: co-evolution of problem-solution", Design Studies, 22 (5), 2001, pp. 425-437.

[22] M.L. Maher, J. Poon, and S. Boulanger, "Formalising Design Exploration as Co-Evolution", Advances in Formal Design Methods for CAD, 1996, pp. 3-30.

[23] H. Makkonen and H. Komulainen, "Explicating the market dimension in the study of digital innovation: a management framework for digital innovation", Technology Analysis \& Strategic Management, 30 (9), 2018, pp. 1015-1028.

[24] Yin R.K., Case Study Research: Design and Methods, Sage Publications, 2014.

[25] K. Ebner, B. Mueller, and F. Ahlemann, "Understanding the success of strategic IT benchmarking-Exploring the role of the individual level", Information \& Management, 56 (5), 2019, pp. 640-656.

[26] Patton M.Q., Qualitative Research \& Evaluation Methods: Integrating Theory and Practice, Sage Publications, 2014.

[27] von Hippel E., Sources of Innovation, NY, 1988.

[28] Miles M.B., Huberman A.M., and J. Saldaña, Qualitative Data Analysis: A Methods Sourcebook, Sage Publications, Arizona State University, 1994.

[29] N. Berente, S. Hansen, J.C. Pike, and P.J. Bateman, "Arguing the Value of Virtual Worlds: Patterns of Discursive Sensemaking of an Innovative Technology", MISQ, 35 (3), 2011, pp. 1-25.

[30] K. Lyytinen and G.M. Rose, "The Disruptive Nature of Information Technology Innovations: The Case of Internet Computing in Systems Development Organizations", MISQ, 27 (4), 2003, pp. 557-595.

[31] A. Afuah and C.L. Tucci, "Crowdsourcing as a Solution to Distant Search", Academy of Management Review, 37 (3), 2012, pp. 355-375.

[32] A.S. Lee and R.L. Baskerville, "Generalizing Generalizability in Information Systems Research", Information Systems Research, 14 (3), 2003, pp. 221243. 